nephron

Practice
Nephron 2018;140:211-217

DOI: $10.1159 / 000492238$
Received: March 29, 2018

Accepted after revision: July 17, 2018

Published online: September 13, 2018

\title{
Role of Albumin Assay on Calcium Levels and Prescription of Phosphate Binders in Chronic Hemodialysis Patients
}

\author{
Camiel L.M. de Roij van Zuijdewijn ${ }^{a}$ Dinky E. de Haseth ${ }^{b}$ Bastiaan van Dam ${ }^{b}$ \\ Willem A. Bax ${ }^{b}$ Muriel P.C. Grooteman ${ }^{a}$ Michiel L. Bots ${ }^{c}$ Peter J. Blankestijn ${ }^{d}$ \\ Menso J. Nubéa Marinus A. van den Dorpel ${ }^{e}$ Pieter M. ter Wee ${ }^{a}$ Erik L. Penne $^{b}$ \\ ${ }^{a}$ Amsterdam UMC, Vrije Universiteit Amsterdam, Department of Nephrology, Amsterdam Cardiovascular Sciences, \\ Amsterdam, The Netherlands; ${ }^{b}$ Department of Internal Medicine, Northwest Clinics, Alkmaar, The Netherlands; \\ 'Julius Center for Health Sciences and Primary Care, University Medical Center, Utrecht University, Utrecht, The \\ Netherlands; ${ }^{d}$ Department of Nephrology and Hypertension, University Medical Center Utrecht, Utrecht University,

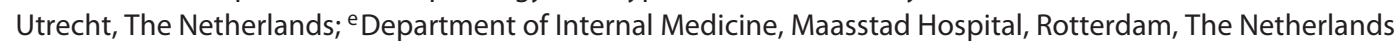

\section{Keywords}

Albumin - Assay · Calcium · Chronic kidney disease-mineral and bone disorder . Hemodialysis . Phosphate-binding agents

\footnotetext{
Abstract

Background/aims: In hemodialysis (HD) patients, the bromcresol green (BCG) assay overestimates, whereas the bromcresol purple (BCP) assay underestimates albumin concentration. Since corrected calcium concentrations depend on albumin, the albumin assay may have implications for the management of bone mineral disorders. Methods: A subset of patients from CONTRAST, a cohort of prevalent HD patients, was analyzed. Bone mineral parameters and prescrip-
}

tion of medication were compared between patients in whom albumin was assessed by BCP versus BCG. Results: Albumin was assessed by BCP in 331 patients (9 of 25 centers) and by BCG in 175 patients ( 16 of 25 centers). Albumin was the lowest in the BCP group $(34.5 \pm 4.2$ vs. $40.3 \pm 3.1 \mathrm{~g} / \mathrm{L}$; $p<0.0005)$. Measured calcium levels and the prescription of calcium-based phosphate binders were similar in both groups. Corrected calcium levels, however, were markedly higher in the BCP group $(2.45 \pm 0.18 \mathrm{vs} .2 .33 \pm 0.18 \mathrm{mmol} / \mathrm{L}$; $p<0.0005)$. Conclusion: These findings suggest that calcium levels are not corrected for albumin in clinical practice when considering the prescription of calcium-free or calciumbased phosphate-binders in dialysis patients.

(c) 2018 The Author(s)

Published by S. Karger AG, Basel

\begin{tabular}{ll}
\hline KARGER & $\begin{array}{l}\text { C } 2018 \text { The Author(s) } \\
\text { Published by S. Karger AG, Basel }\end{array}$ \\
E-Mail karger@karger.com & This article is licensed under the Creative Commons Attribution- \\
www.karger.com/nef & $\begin{array}{l}\text { NonCommercial-NoDerivatives 4.0 International License (CC BY- } \\
\text { NC-ND) (http://www.karger.com/Services/OpenAccessLicense). } \\
\text { Usage and distribution for commercial purposes as well as any dis- } \\
\text { tribution of modified material requires written permission. }\end{array}$
\end{tabular}

Dr. Erik L. Penne

Department of Internal Medicine

Northwest Clinics, Wilhelminalaan 12

NL-1815 JD Alkmaar (The Netherlands)

E-Mail e.l.penne@nwz.nl 


\section{Introduction}

Mineral metabolism disorders, such as hyperphosphatemia and hypercalcemia, are associated with increased cardiovascular morbidity and mortality in patients with chronic kidney disease (CKD) [1-3]. Hence, the current Kidney Disease Improving Global Outcomes (KDIGO) clinical practice guideline on the management of $\mathrm{CKD}$ mineral and bone disorder (MBD) suggests lowering elevated phosphate levels toward the normal range and avoiding hypercalcemia [4].

Phosphate-lowering treatment is indicated in patients with persistently elevated phosphate levels. However, calcium-based phosphate binders may contribute to a positive calcium balance in CKD patients [5] and may accelerate vascular calcification [6-8]. Hence, the KDIGO Work Group suggests restricting the dose of calciumbased phosphate binders [4].

More than $50 \%$ of the plasma calcium is bound to albumin. Only the ionized calcium fraction is biologically active [9]. In clinical practice, however, the ionized calcium fraction is not routinely available. Instead, total calcium concentration is measured and can subsequently be corrected for the albumin level $[3,9]$. Data from clinical studies investigating differences in clinical outcomes using corrected versus total calcium levels are lacking. Nevertheless, in many laboratories and clinical trial databases, corrected calcium levels are reported [3]. This correction, however, is complicated by the existence of different albumin assays. Albumin concentrations are usually measured with a dye-binding assay, that is, the bromcresol purple (BCP) or the bromcresol green (BCG) assay. Notably, especially in hemodialysis (HD) patients, albumin levels assessed with these methods deviate from albumin levels as assessed with an immunological method, which is considered the reference standard. When compared to the immunological method, the BCP assay underestimates, whereas the BCG overestimates the albumin level [10-12]. Consequently, the corrected calcium level depends on the albumin assay that is used [13]. Mean corrected calcium levels will possibly be higher in centers using BCP assay as compared to centers using the BCG assay, potentially leading to differences in prescription of phosphate binders, calcitriol, or vitamin $\mathrm{D}$. The albumin assay type may thus affect clinical decisions in the management of bone mineral disorders.

In the present study, an exploratory analysis was performed to investigate (1) differences in albumin levels determined by either the BCG or the BCP assay, (2) a possible difference in corrected calcium levels between the

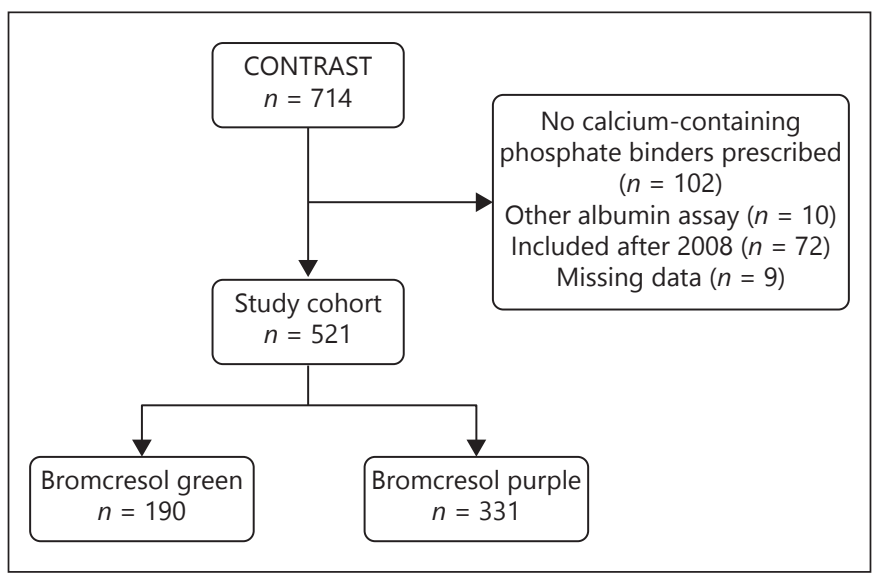

Fig. 1. Flowchart of patient inclusion.

$\mathrm{BCP}$ and BCG group and (3) possible differences in the prescription of (non) calcium-based phosphate binders between these groups.

\section{Materials and Methods}

For this study, baseline data of patients from the CONvective TRAnsport STudy (CONTRAST, clinicaltrials.gov identifier NCT00205556) were analyzed $[14,15]$. Prevalent intermittent HD patients were recruited from dialysis centers in Canada $(n=2)$, Norway $(n=1)$, and the Netherlands $(n=26)$. All patients were at least 18 years of age and treated with low-flux HD 2 or 3 times weekly for at least 2 months. A life expectancy of less than 3 months due to non-renal disease, participation in another clinical intervention trial evaluating cardiovascular outcome, or severe incompliance to dialysis prescription was defined as exclusion criteria. At the time of study initiation, routine patient care was performed according to local guidelines, based on the National Kidney Foundation's Kidney Disease Outcomes Quality Initiative (KDOQI) Clinical Practice Guidelines for Bone Metabolism and Disease in CKD 2003 [16]. The composition of dialysis fluid, including calcium concentration, and medication was based on the clinical judgment of the local nephrologist. CONTRAST was conducted in accordance with the Declaration of Helsinki and approved by a central and all local medical ethics review boards.

\section{Eligible Patients}

As shown in Figure 1, a total of 521 patients from 25 centers were included in the present cross-sectional analysis. Only patients from centers were included in which both calcium-based and calcium-free phosphate binders were regularly prescribed, thereby excluding 102 subjects from 2 centers. Furthermore, patients from 1 center where neither the BCP nor the BCG method was used to measure albumin were excluded $(n=10)$. Patients were included in this study until 2008 because the KDIGO Clinical Practice Guidelines for the Diagnosis, Evaluation, Prevention, and Treatment of CKD-MBD was published in 2009 [3], which may have 
affected treatment policy (excluding 72 patients). Lastly, patients with missing values of calcium, albumin, or phosphate at baseline were excluded $(n=9)$.

\section{Data Collection}

Baseline data from the CONTRAST study were used, including demographic, clinical, and treatment-related parameters. Blood samples were drawn prior to dialysis. Laboratory samples were analyzed at the local hospital laboratory facility. Calcium concentrations were corrected for albumin using the formula by Payne et al. [17]: adjusted calcium $(\mathrm{mmol} / \mathrm{L})=([$ uncorrected calcium $[\mathrm{mmol} / \mathrm{L}])+0.0246 \times(40-[$ albumin $(\mathrm{g} / \mathrm{L})])$. We also analyzed our data using the formula by Orrell et al. [18]: corrected calcium $(\mathrm{mmol} / \mathrm{L})=($ uncorrected calcium $[\mathrm{mmol} / \mathrm{L}])+0.0176 \times(34-[\mathrm{al}-$ bumin $(\mathrm{g} / \mathrm{L})])$. Furthermore, data on the prescription of phosphate binders, vitamin $\mathrm{D}$ were collected. Of note, calcimimetics (i.e., cinacalcet) were not prescribed at the time of the study. Nutritional status was assessed using the 7-point scaled Subjective Global Assessment (SGA) [19].

\section{Statistical Analysis}

Baseline data are shown as mean (SD), median (interquartile range), or number (percentage) when appropriate. Differences between patients in whom albumin was measured with the BCP assay (BCP group) and in whom albumin was assessed using the BCG assay (BCG group) were assessed using a $t$ test for normally distributed continuous variables, a Mann-Whitney U test for not-normally distributed continuous variables or a $\chi^{2}$-test for categorical variables. To assess whether a potential difference between albumin assay groups in corrected calcium was mediated by center differences, a linear regression was performed with corrected calcium as the dependent variable and albumin assay and center (categorical) as independent variables. All model assumptions were checked and not violated. A 2 -sided $p$ value $<0.05$ was considered statistically significant. All statistical analyses were performed using IBM SPSS Statistics version 22.0 (IBM SPSS Inc., IL, USA).

\section{Sensitivity Analysis}

As a sensitivity analysis, hypercalcemic patients, with a corrected calcium level $>2.55 \mathrm{mmol} / \mathrm{L}$, were identified. Possible differences in the prescription of (non) calcium-based phosphate binders were also analyzed in this subgroup.

\section{Results}

\section{Patient Characteristics}

Characteristics of patients as stratified by the albumin assay (BCP $n=331$ [ 9 centers] and BCG $n=190$ [15 centers]) are shown in Table 1. Overall, the mean age was $63.5 \pm 14.1$ years and $62 \%$ were male. Albumin level was significantly lower in the BCP group $(34.5 \pm 4.2 \mathrm{~g} / \mathrm{L}) \mathrm{com}$ pared to the BCG group $(40.3 \pm 3.1 \mathrm{~g} / \mathrm{L})$. More patients in the BCG group had residual kidney function (58\%) when compared to the BCP group (49\%). In addition, more patients in the BCG group had a normal SGA $(88 \%)$ when compared to the patients in the BCP group (81\%).

Albumin Assay and Corrected Calcium in HD

\section{Bone Mineral Parameters}

Comparing the albumin assay groups, the mean measured calcium was similar in both groups $(2.32 \pm 0.18$ and $2.34 \pm 0.17 \mathrm{mmol} / \mathrm{L}$ for BCP and BCG respectively $[p=$ $0.26]$ ). In the BCP group, 9.1\% was hypercalcemic (measured calcium $>2.55 \mathrm{mmol} / \mathrm{L}$ ), which was similar to that in the BCG group (9.5\%). Albumin-corrected calcium was higher in the BCP group $(2.45 \pm 0.18 \mathrm{mmol} / \mathrm{L})$ than that in the BCG group $(2.33 \pm 0.18 \mathrm{mmol} / \mathrm{L})$. Correction for center differences and nutritional status (SGA) did not alter the difference between corrected calcium levels between the 2 albumin assay groups (corrected unstandardized $\beta=0.16,95 \%$ CI $0.08-0.24$ ). In the BCP group, $27.5 \%$ of the patients were hypercalcemic (corrected calcium $>2.55 \mathrm{mmol} / \mathrm{L}$ ) versus $12.1 \%$ of the patients in the BCG group. Albumin-corrected calcium using the Orrell et al. [19] formula resulted in similar outcomes. With this formula, the prevalence of hypercalcemia was lower in both groups (8.5 and 4.2\% for BCP and BCG respectively).

Phosphate levels were found to be higher in the BCP group compared to those in the BCG group ( $1.70 \pm 0.53 \mathrm{vs.}$ $1.58 \pm 0.44 \mathrm{mmol} / \mathrm{L}$ respectively). In the BCP group, a smaller percentage of patients achieved KDOQI treatment targets for phosphate (phosphate $<1.78 \mathrm{mmol} / \mathrm{L} ; 58.6$ vs. $74.2 \%)$.

\section{CKD-MBD Medication Prescription}

Prescription of calcium-based phosphate binders (calcium carbonate, calcium acetate) did not differ in the 2 albumin assay groups despite higher corrected calcium levels in the BCP group (51 and 45\%). The prescription of calcium-free phosphate binders (sevelamer, lanthanum carbonate) was also similar between the 2 groups (69 and $70 \%)$. Vitamin D supplementation was prescribed in 213 out of $331 \mathrm{BCP}$ patients (64\%) and in 135 out of 190 of BCG patients $(71 \%)$. In $93.5 \%$ of these patients, the type of vitamin D was alfacalcidol. Furthermore, in a subgroup of hypercalcemic patients, no differences were found between the BCP and the BCG group regarding the prescription of calcium-based phosphate binders (52 and $48 \%$, respectively), calcium-free phosphate binders (69 and $57 \%$ ), or vitamin D (63 and 65\%).

\section{Discussion}

Results from this study confirm that albumin levels of patients in whom albumin was measured with the BCP assay are lower as compared to patients in whom albumin 
Table 1. Patient characteristics

\begin{tabular}{|c|c|c|c|c|}
\hline \multicolumn{5}{|l|}{ Demographic variables } \\
\hline Age, years & $63.5(14.1)$ & $63.3(14.0)$ & $63.9(14.5)$ & 0.62 \\
\hline Gender, male & $323(62)$ & $201(61)$ & $122(64)$ & 0.43 \\
\hline $\mathrm{BMI}, \mathrm{kg} / \mathrm{m}^{2}$ & $24.8(4.2)$ & $24.9(4.5)$ & $24.8(3.8)$ & 0.82 \\
\hline SGA (normal, score 6-7) & $433(83)$ & $268(81)$ & $167(88)$ & 0.01 \\
\hline Diabetes & $102(20)$ & $66(20)$ & $36(19)$ & 0.77 \\
\hline Cardiovascular disease & $224(43)$ & $140(42)$ & $84(44)$ & 0.67 \\
\hline Residual kidney function* & $272(52)$ & $162(49)$ & $110(58)$ & 0.05 \\
\hline \multicolumn{5}{|l|}{ Dialysis parameters } \\
\hline Dialysis vintage & $2.0(1.0-3.8)$ & $2.0(0.9-3.7)$ & $2.0(1.2-4.0)$ & 0.33 \\
\hline Cholesterol, mmol/L & $3.65(0.98)$ & $3.59(0.99)$ & $3.76(0.95)$ & 0.06 \\
\hline Creatinine, $\mu \mathrm{mol} / \mathrm{L}$ & $876(253)$ & $895(239)$ & $844(273)$ & 0.03 \\
\hline Phosphate, mmol/L & $1.65(0.50)$ & $1.70(0.53)$ & $1.58(0.44)$ & 0.01 \\
\hline Albumin, $\mathrm{g} / \mathrm{L}$ & $36.6(4.7)$ & $34.5(4.2)$ & $40.3(3.1)$ & $<0.0005$ \\
\hline Uncorrected calcium, $\mathrm{mmol} / \mathrm{L}$ & $2.32(0.18)$ & $2.32(0.18)$ & $2.34(0.17)$ & 0.26 \\
\hline Corrected calcium ${ }^{\#}, \mathrm{mmol} / \mathrm{L}$ & $2.41(0.19)$ & $2.45(0.18)$ & $2.33(0.18)$ & $<0.0005$ \\
\hline Corrected calcium ${ }^{£}, \mathrm{mmol} / \mathrm{L}$ & $2.28(0.18)$ & $2.31(0.18)$ & $2.22(0.17)$ & $<0.0005$ \\
\hline $\mathrm{PTH}, \mathrm{pmol} / \mathrm{L}$ & $29(9-35)$ & $19(9-36)$ & $20(9-35)$ & 0.87 \\
\hline \multicolumn{5}{|l|}{ Medication use } \\
\hline \multicolumn{5}{|l|}{ Calcium-containing } \\
\hline phosphate binders $\S$ & $256(49)$ & $170(51)$ & $86(45)$ & 0.19 \\
\hline \multicolumn{5}{|l|}{ Calcium-free phosphate } \\
\hline
\end{tabular}

Data are shown are mean (SD), median (interquartile range) or number (percentage), when appropriate.

* Defined as diuresis $>100 \mathrm{~mL} / 24 \mathrm{~h}$.

\# Albumin corrected calcium as calculated by the formula by Payne et al. [17].

${ }^{£}$ Albumin corrected calcium as calculated by the formula by Orrell et al. [18].

$\S$ Calcium carbonate and/or calcium acetate.

" Lanthanum and/or sevelamer.

Conversion factors for units: haematocrit in $\mathrm{L} / \mathrm{L}$ to $\%,(\times 100)$; cholesterol in $\mathrm{mmol} / \mathrm{L}$ to $\mathrm{mg} / \mathrm{dL},(/ 0.02586)$, creatinine in $\mu \mathrm{mol} / \mathrm{L}$ to $\mathrm{mg} / \mathrm{dL}$ (/88.4); phosphate in $\mathrm{mmol} / \mathrm{L}$ to $\mathrm{mg} / \mathrm{dL},(/ 0.3229)$; albumin in $\mathrm{g} / \mathrm{L}$ to $\mathrm{g} / \mathrm{dL},(/ 10)$; calcium in $\mathrm{mmol} / \mathrm{L}$ to $\mathrm{mg} / \mathrm{dL}(/ 0.25) ; \mathrm{PTH}$ in $\mathrm{pmol} / \mathrm{L}$ to $\mathrm{pg} / \mathrm{mL}(/ 0.106)$.

BMI, body mass index; SGA, subjective global assessment; PTH, parathyroid hormone.

levels were measured with the BCG assay. Measured calcium levels were similar, but the 2 albumin assays resulted in significantly different corrected calcium levels. Similarly, the prevalence of hypercalcemia was similar in the 2 groups when considering uncorrected calcium level. However, after correction of albumin, the prevalence of hypercalcemia was more than 2 times higher in the BCP group compared to that of the BCG group. Importantly, no difference was found in the prescription of calciumbased phosphate binders between the 2 groups.

Hypercalcemia is associated with increased mortality and should be avoided in HD patients [20]. Hence, it is important to take calcium levels into account in the treatment of mineral bone disease, in particular, in view of the increased serum calcium concentrations caused by calcium-based phosphate binders and vitamin D supplements 
[21]. In the 2003 KDOQI guideline on CKD-MBD [16], which was the guideline at the time the data for this study were collected, it was advised that calcium levels be maintained within the normal range and preferably toward the lower end of normal. No preference for either calciumfree or calcium-based phosphate binders was defined, as long as elemental calcium intake did not exceed 1,500 mg/ day, with the exception for HD patients with severe calcifications, for whom calcium-free phosphate binders were advised. This explains the relatively high use of calciumbased phosphate binders as reported in this study. Notably, it was recommended to correct serum calcium levels for albumin concentration. In the event of high corrected calcium levels, the dose of calcium-based phosphate binders and/or vitamin $\mathrm{D}$ analogues had to be reduced or discontinued. Notably, the 2009 KDIGO guideline on CKD-MBD [3] stated that there were in fact no data supporting the use of corrected calcium levels versus uncorrected calcium levels in clinical practice, a conclusion mainly based on the study by Gauci et al. [22]. However, the KDIGO Working Group did not recommend that corrected calcium measurements be abandoned [3]. It was emphasized that the assay used for albumin may affect the corrected calcium level, as described by Labriola et al. [13] and also confirmed by our data. In the recent KDIGO 2017 CKD-BMD guideline update, no further statements about corrected versus uncorrected calcium levels were made. A major change in this update in comparison with the previous guidelines was recommending tighter restrictions in the use of calcium-based phosphate binders $[4,23]$.

Ionized calcium is considered the reference standard [24]. However, this method is not routinely used in clinical practice due to logistic feasibility and costs. As mentioned before, it is presently unclear whether measured or corrected calcium should be used in clinical practice. Furthermore, multiple formulas are available to correct the measured calcium level for albumin concentration. The most widely used formula was developed by Payne et al. [17] who analyzed 200 patients undergoing liver function tests and derived a simple regression equation from these data to correct calcium for albumin. However, Payne et al. [17] did not measure ionized calcium for comparison. A more recent study compared various methods to adjust calcium levels for albumin in $50 \mathrm{HD}$ subjects [25]. In that study, it appeared that corrected calcium levels have no added value in clinical practice over uncorrected calcium levels in predicting ionized calcium. In fact, corrected calcium levels using the formula derived by Payne et al. [17] was even inferior to uncorrected calcium levels in pre-

Albumin Assay and Corrected Calcium in HD dicting ionized calcium, whereas the formula by Orrell performed slightly better [18]. Notably, both formulas were created in cohorts in whom all albumin was measured using the BCG assay. None of these studies did address differences between the BCP and BCG assays in correcting calcium. Therefore, it is debatable whether these formulas can be extrapolated to cohorts in which albumin is measured using the BCP assay. Kok et al. [12] demonstrated that the $\mathrm{BCP}$ assay is affected to a much higher extent by carbamylation of albumin than the BCG assay, suggesting that the apparent mild hypoalbuminemia in this group is a measurement error. From these data, it can be postulated that calcium should not be corrected for mild hypoalbuminemia when albumin is assessed with the BCP assay.

A limitation of the present study is the unavailability of data on locally prescribed dialysate calcium levels. However, even when available, the mechanisms by which different prescribed dialysate calcium levels could have affected serum calcium concentration, phosphate concentration, or drug-prescription dependent of the measurement method of albumin would remain unclear. Furthermore, the measurement of albumin with both assays was not done in parallel. Another limitation is that ionized calcium for comparison was not measured. The most important strength of our study is the meticulous data collection in this well-defined cohort of HD patients, including medication prescription. Furthermore, as both calcium-free and calcium-containing phosphate binders were fully reimbursed by insurance companies, financial motives appear to play no role in the prescription of phosphate binder type.

In summary, the BCP albumin assay results in lower measured albumin concentration in HD patients when compared to albumin concentration obtained using the BCG assay. Measured calcium levels were similar, but the 2 different albumin assays resulted in significantly different corrected calcium levels. In addition, the prescription of calcium-containing phosphate binders was similar in both groups. Thus, it appears that in clinical practice, calcium levels are not corrected for albumin when considering the prescription of (non) calcium-containing phosphate binders. From our data, it is unclear whether this is justified.

\section{Acknowledgments}

We are grateful to all patients and staff who participated in this project. 


\section{Ethical Statement}

The study was conducted in accordance with the Declaration of Helsinki and approved by a central and all local medical ethics review boards. Written informed consent was obtained from all patients prior to the study.

\section{Disclosure Statement}

According to the authors, there are no conflicts of interest to declare.

\section{Funding Source}

CONTRAST was financially supported by a grant from the Dutch Kidney Foundation (Nierstichting Nederland, grant C02.2019) and unrestricted grants from Fresenius Medical Care (The Netherlands) and Gambro Lundia AB (Sweden). Additional support was received from the Dr. E.E. Twiss Fund, Roche Netherlands, the International Society of Nephrology/Baxter Extramural Grant Program and the Dutch Organization for Health Research and Development (ZonMW, grant 17088.2802).

\section{Consent for Publication}

All authors approved the manuscript for publication.

\section{Availability of Data and Material}

The datasets analyzed during the study are not publicly available due to privacy issues but are available from the corresponding author on reasonable request.

\section{Author Contribution}

B.D., W.A.B., M.P.C.G., M.L.B., P.J.B., M.J.N., M.A.D., P.M.W., and E.L.P. were responsible for the concept and design of the study. Data collection was performed by M.P.C.G., M.L.B., P.J.B., M.J.N., M.A.D., P.M.W., and E.L.P. Data analysis and interpretation was conducted C.L.M.R.Z., D.E.H., B.D., W.A.B., and E.L.P. Statistical analysis was handled by C.L.M.R.Z., D.E.H., and E.L.P. The article was drafted by C.L.M.R.Z., D.E.H., and E.L.P. Critical revision of the article was carried out by B.D., W.A.B., M.P.C.G., M.L.B., P.J.B., M.J.N., M.A.D., and P.M.W. All authors approved of the final article.

\section{References}

1 Tentori F, Blayney MJ, Albert JM, Gillespie BW, Kerr PG, Bommer J, Young EW, Akizawa T, Akiba T, Pisoni RL, Robinson BM, Port FK: Mortality risk for dialysis patients with different levels of serum calcium, phosphorus, and PTH: the dialysis outcomes and practice patterns study (DOPPS). Am J Kidney Dis 2008;52:519-530

2 Lee YT, Ng HY, Chiu TT, Li LC, Pei SN, Kuo WH, Lee CT: Association of bone-derived biomarkers with vascular calcification in chronic hemodialysis patients. Clin Chim Acta 2016;452:38-43.

3 KDIGO clinical practice guideline for the diagnosis, evaluation, prevention, and treatment of chronic kidney disease-mineral and bone disorder (CKD-MBD). Kidney Int Suppl 2009;S1-S130.

4 KDIGO 2017 clinical pGuideline update for the diagnosis, evauation, prevention, and treatment of chronic kidney disease-mineral and bone disorder (CKD-MBD). Kidney Int Suppl 2017;7:1-59.

5 Hill KM, Martin BR, Wasney ME, McCabe GP, Moe SM, Weaver CM, Peacock M: Oral calcium carbonate affects calcium but not phosphorus balance in stage 3-4 chronic kidney disease. Kidney Int 2013;83:959-966.

6 Block GA, Wheeler DC, Persky MS, Kestenbaum B, Ketteler M, Spiegel DM, Allison MA, Asplin J, Smits G, Hoofnagle AN, Kooienga L, Thadhani R, Mannstadt M, Wolf M, Chertow GM: Effects of phosphate binders in moderate CKD. J Am Soc Nephrol 2012;23: 1407-1415.

7 Di Iorio B, Molony D, Bell C, Cucciniello E, Bellizzi V, Russo D, Belassi A, INDEPENDENT Study Investigators: Sevelamer versus calcium carbonate in incident hemodialysis patients: results of an open-label 24-month randomized clinical trial. Am J Kidney Dis 2013;62:771-778

8 Block GA, Spiegel DM, Ehrlich J, Mehta R, Lindbergh J, Dreisbach A, Raggi P: Effect of sevelamer and calcium on coronary artery calcification in patients new to hemodialysis. Kidney Int 2005;68:1815-1824.

9 Morton AR, Garland JS, Holden RM: Is the calcium correct? Measuring serum calcium in dialysis patients. Semin Dial 2010;23:283289.

10 Mabuchi $\mathrm{H}$, Nakahashi $\mathrm{H}$ : Underestimation of serum albumin by the bromcresol purple method and a major endogenous ligand in uremia. Clin Chim Acta 1987;167:89-96.

11 Carfray A, Patel K, Whitaker P, Garrick P, Griffiths GJ, Warwick GL: Albumin as an outcome measure in haemodialysis in patients: the effect of variation in assay method. Nephrol Dial Transplant 2000;15:1819-1822.

12 Kok MB, Tegelaers FP, van Dam B, van Rijn JL, van Pelt J: Carbamylation of albumin is a cause for discrepancies between albumin assays. Clin Chim Acta 2014;434:6-10.

13 Labriola L, Wallemacq P, Gulbis B, Jadoul M: The impact of the assay for measuring albu- min on corrected ("adjusted") calcium concentrations. Nephrol Dial Transplant 2009; 24:1834-1838.

14 Grooteman MP, van den Dorpel MA, Bots ML, Penne EL, van der Weerd NC, Mazairac $\mathrm{AH}$, den Hoedt $\mathrm{CH}$, van der Tweel I, Lévesque R, Nubé MJ, ter Wee PM, Blankestijn PJ, CONTRAST Investogators: Effect of online hemodiafiltration on all-cause mortality and cardiovascular outcomes. J Am Soc Nephrol 2012;23:1087-1096.

15 Penne EL, Blankestijn PJ, Bots ML, van den Dorpel MA, Grooteman MP, Nubé MJ, van der Tweel I, ter Wee PM, the CONTRAST study group: Effect of increased convective clearance by on-line hemodiafiltration on all cause and cardiovascular mortality in chronic hemodialysis patients - the Dutch CONvective TRAnsport STudy (CONTRAST): rationale and design of a randomised controlled trial [ISRCTN38365125]. Curr Control Trials Cardiovasc Med 2005;6:8.

16 National Kidney Foundation: K/DOQI clinical practice guidelines for bone metabolism and disease in chronic kidney disease. Am J Kidney Dis 2003;42(4 suppl 3):S1-S201.

17 Payne RB, Little AJ, Williams RB, Milner JR: Interpretation of serum calcium in patients with abnormal serum proteins. Br Med J 1973;4:643-646.

18 Orrell DH: Albumin as an aid to the interpretation of serum calcium. Clin Chim Acta 1971;35:483-489. 
19 Adequacy of dialysis and nutrition in continuous peritoneal dialysis: association with clinical outcomes. Canada-USA (CANUSA) Peritoneal Dialysis Study Group. J Am Soc Nephrol 1996;7:198-207.

20 Miller JE, Kovesdy CP, Norris KC, Mehrota R, Nissenson AR, Kopple JD, Kalantar-Zadeh K: Association of cumulatively low or high serum calcium levels with mortality in longterm hemodialysis patients. Am J Nephrol 2010;32:403-413.

21 Toida T, Fukudome K, Fujimoto S, Yamada K, Sato Y, Chiyotanda S, Kitamura K: Effect of lanthanum carbonate vs. calcium carbon- ate on serum calcium in hemodialysis patients: a crossover study. Clin Nephrol 2012; 78:216-223.

22 Gauci C, Moranne O, Fouqueray B, de la Faille R, Maruani G, Haymann JP, Jacquot C, Boffa JJ, Flamant M, Rossert J, Urena P, Stengel B, Souberbielle JC, Froissart M, Houillier P, NephroTest Study Group: Pitfalls of measuring total blood calcium in patients with CKD. J Am Soc Nephrol 2008; 19 : 1592-1598.

23 Isakova T, Nickolas TL, Denburg M, Yarlagadda S, Weiner DE, Gutierrez OM, Bansal V, Rosas SE, Nigwekar S, Yee J,
Kramer H: KDOQI US commentary on the 2017 KDIGO clinical practice guideline update for the diagnosis, evaluation, prevention, and treatment of chronic kidney disease-mineral and bone disorder (CKDMBD). Am J Kidney Dis 2017;70:737-751.

24 Goransson LG, Skadberg O, Bergrem H: Albumin-corrected or ionized calcium in renal failure? What to measure? Nephrol Dial Transplant 2005;20:2126-2129.

25 Clase CM, Norman GL, Beecroft ML, Churchill DN: Albumin-corrected calcium and ionized calcium in stable haemodialysis patients. Nephrol Dial Transplant 2000;15:1841-1846. 